\title{
Accounting for Thermal Resistance of Cooling Water Fouling in Plate Heat Exchangers
}

\author{
Olga P. Arsenyeva ${ }^{\star a}$, Leonid L. Tovazhnyansky ${ }^{\mathrm{b}}$, Petro O. Kapustenko ${ }^{\mathrm{b}}$, \\ Oleksiy V. Demirskyy ${ }^{a}$
}

\begin{abstract}
aO "Sodrugestvo-T", Krasnoznamenniy per. 2, k. 19, 61002 Kharkiv, Ukraine; 'National Technical University "KhPI”, 21 Frunze Str., 61002 Kharkiv, Ukraine; sodrut@gmail.com
\end{abstract}

The Plate Heat Exchanger (PHE) is one of the most efficient types of modern heat exchangers. Heat transfer enhancement is one of the main features of PHEs, and lower fouling tendencies render them even more advantages for the use in different applications. The effects on fouling accumulation rate of process parameters in PHE channels of intricate geometry are studied in this article. The asymptotic behavior of the water fouling on heat transfer surfaces is examined. The fouling accumulation rate is described as a difference between the fouling deposition term and the fouling removal term. On comparison with data for fouling on different heat transfer surfaces available in literature it is shown that asymptotic fouling thermal resistance inversely proportional to wall shear stress. The proportionality coefficient in this relation is determined for a number of considered cases. To calculate the wall shear stress the equation for PHE channel main corrugated field is used, which accounts for corrugations geometrical parameters. It is shown that for given fouling properties of water this coefficient is constant and can be determined by monitoring fouling behavior of any item of heat exchangers working on specific enterprise. After that all other heat exchangers of that enterprise can be calculated using that data and developed Equation for accounting of fouling in their design.

\section{Introduction}

New challenges in efficient heat recuperation arise when integrating renewables, polygeneration and CHP units with traditional sources of heat in industry and the communal sector, as it is shown by Klemes et al. (2010). The Plate Heat Exchanger (PHE) is the one of most efficient types of modern heat exchange equipment, which satisfies this requirement. The design and operation principles of PHE are sufficiently well described elsewhere see e.g. Wang et al. (2007), Shah and Sekulić (2003), Tovazhnyansky et al. (2004). The heat transfer processes in this heat exchanger takes place in the channels of complex geometry formed by plates pressed from thin metal. The plates' corrugation form influences strongly on heat and hydraulic behaviour of inter-plate channels; the effect is similar to that in enhanced tubes, see e.g. Kukulka et al. (2010), Wang et al. (2009).

Analysing different methods for mitigation of water fouling Panchal and Knudsen (1998) characterized the use of enhanced heat transfer surfaces as one of the major categories. Heat transfer enhancement is one of the main features of PHEs and mitigation of fouling render even more advantages to the use of this type of heat transfer equipment in different applications at process industries. To define operation limits and optimal design of PHE to minimize fouling we need to estimate the effects on fouling accumulation rate of process parameters in PHE channels of intricate geometry.

Please cite this article as: Arsenyeva O. P., Tovazhnyansky L. L., Kapustenko P. O. and Demirskyy O. V., (2012), Accounting for thermal resistance of cooling water fouling in plate heat exchangers, Chemical Engineering Transactions, 29, 1327-1332 
To select heat exchanger for cooling of process fluid design engineer must strictly satisfy thermal and hydraulic conditions on the process side. The initial temperature of cooling water as well as its quality also cannot be influenced by designer. These parameters are the same for any type of heat exchanger which can be utilized on this process position - tubular, different kinds of PHEs or others. In general case we can vary the flow rate and hence the outlet temperature of cooling water, but it is also frequently strictly specified due to constraints of a whole cooling system of the enterprise. Only internal parameters of PHE construction can be varied, like number, size and corrugation pattern of plates, streams passes numbers. It can lead to different channel geometries, flow velocities and wall temperatures inside the heat exchanger. Therefore the influence of these parameters has primary importance for prediction of fouling accumulation rate and its control.

As it is pointed out for tubular heat exchangers in TEMA standards (2007), currently five different types of fouling mechanisms are recognized:

- Precipitation

- Particulate

- Chemical reaction

- Corrosion

- Biological

The mitigation of corrosion fouling in PHEs can be achieved by using appropriate corrosion resistant steels, which can be much more economical than in shell and tubes due to much smaller surface area for the same conditions and thinner walls of plates, down to $0.5-0.3 \mathrm{~mm}$. Most of the models describing the other fouling mechanisms are based on prediction of fouling accumulation rate as a difference between fouling deposition term $\varphi_{d}$ and fouling removal term $\varphi_{r}$ :

$$
\frac{d \delta}{d t}=\varphi_{d}-\varphi_{r}
$$

where $\delta$ - fouling thickness, $\mathrm{mm} ; t$ - time, s.

When $\varphi_{d}$ equal $\varphi_{r}$ the layer of deposits not grow. It is possible in two ways: a) The removal is stronger than the adhesion of fouling to the wall surface, only after some threshold conditions the fouling accumulation can start, as shown by Yang and Crittenden (2012); b) The removal rate is directly proportional to thickness of deposits $\delta$, or deposition rate is inversely proportional to $\delta$. In this case after some time $t^{*}$ the deposition thickness is stabilizing to certain asymptotic value $\delta^{*}$.

\section{Asymptotic values of fouling thermal resistance}

The asymptotic behavior of water fouling on heat transfer surfaces was observed by many researchers, see Panchal and Knudsen (1998). It happens usually after stream velocity reach significant enough values, which ensure certain level of shear stress $T_{w}$ on the wall. Let's assume, that at asymptotic fouling conditions all effects contributing to fouling grows are accounted for by deposition term $\varphi_{d}{ }^{*}$ and all mitigation effects are accounted by removal term $\varphi_{r}{ }^{*}$. Another assumption we made is that $\varphi_{r}{ }^{*}$ proportional to shear stress on the wall in certain power $m$ and deposit thickness $\delta^{*}$ :

$$
\varphi_{r}^{*}=b \cdot \tau_{w}^{m} \cdot \delta^{*}
$$

where $b$ is proportionality coefficient, $[1 /(\mathrm{Pa} \cdot \mathrm{s})]$.

When the deposition thickness reach asymptotic value, its time derivative equal to zero and from Eq. 1 follows:

$\delta^{*}=\varphi_{d}^{*} /\left(b \cdot \tau_{w}^{m}\right)$

Then the asymptotic value of fouling thermal resistance, knowing the fouling deposit thermal conductivity $\lambda_{f}$, can be expressed as:

$R_{f}^{*}=B^{*} \cdot \tau_{w}^{-m}$,

where $B^{*}=\varphi_{d}^{*} /\left(b^{*} \cdot \lambda_{f}^{*}\right)$.

The comprehensive study of particulate water fouling in PHE channels was reported by Karabelas et al, (1997). The experiments were made for PHE channels formed by commercial plates with 
corrugation inclination angle $60^{\circ}$ and $30^{\circ}$. The asymptotic behavior with a time of fouling thermal resistance was observed, as well as strong influence of flow velocity.

We have estimated wall shear stress on a main corrugated field of inter-plate channels using Equation:

$\tau_{w}=\zeta_{s} \cdot \psi \cdot \rho \cdot w^{2} / 8$

The friction factor of total pressure losses (due to friction on the wall and form drag) calculated using formula proposed in paper by Arsenyeva et al. (2011). The share of friction losses $\psi$ estimated by Equation proposed in paper by Kapustenko et al. (2011):

$$
A=380 /[\operatorname{tg}(\beta)]^{1.75} \text {; at } \operatorname{Re}>A \quad \psi=(\operatorname{Re} / A)^{-0.15 \cdot \sin (\beta)} \text {; at } \operatorname{Re} \leq A \quad \psi=1 \text {. }
$$

Here $\beta$ - the corrugation inclination angle to plate longitudinal axis. The Reynolds number $\operatorname{Re}$ is calculated for velocities presented in paper by Karabelas et al, (1997), water properties at temperature $40{ }^{\circ} \mathrm{C}$ and equivalent diameter $\mathrm{D}_{\mathrm{e}}=0.005 \mathrm{~mm}$. The corrugation aspect ratio assumed as $\gamma=0.581$.

The experimental data on fouling from that paper are plotted against wall shear stress in Figure1. The influence of wall shear stress on asymptotic thermal resistance of fouling is distinctly seen. Data correlated by Eq. 4 with $\mathrm{m}=1$ and $B^{*}=3.5 \cdot 10^{-4} \mathrm{~K} \cdot \mathrm{s} / \mathrm{m}$ (solid line in Figure 1 ). For wall shear stress higher than $40 \mathrm{~Pa}$, thermal resistance becomes very small (less than $10^{-5} \mathrm{~m}^{2} \mathrm{~K} / \mathrm{W}$ ) and data unstable.

The process of calcium sulfate fouling in PHEs was investigated by Bansal et al. $(2000,2008)$ on a PHE made from commercial plates with chevron corrugations. The corrugations inclination angle $\beta=$ $60^{\circ}$. To investigate velocity effect there are three experimental runs with velocities $0.183 \mathrm{~m} / \mathrm{s}, 0.352$ $\mathrm{m} / \mathrm{s}$ and $0.667 \mathrm{~m} / \mathrm{s}$. All other conditions were the same. We have estimated wall shear stresses using Eq. 5 and Eq.6, as described above. For water temperature $610 \mathrm{C}, \mathrm{De}=0.005 \mathrm{~mm}, \mathrm{y}=0.581$. Two points on Figure 1 correspond to fouling thermal resistances at the end of runs (after 7,000 $\mathrm{min}$ ), velocities $0.352 \mathrm{~m} / \mathrm{s}$ and $0.667 \mathrm{~m} / \mathrm{s}$. The test run at lowest velocity finished after only $2,000 \mathrm{~min}$ and do not permit to estimate $\mathrm{Rf}^{*}$. Data correlated by Eq. 4 with $\mathrm{m}=1$ and $\mathrm{B}^{*}=2.05 \cdot 10^{-4} \mathrm{~K} \cdot \mathrm{s} / \mathrm{m}$.

The fouling process of calcium carbonate on the surface of inner tube in annulus channel was investigated experimentally by Zhenhua et al. (2008). There two test runs at velocities 0.6 and $1.2 \mathrm{~m} / \mathrm{s}$ with all other conditions the same. Estimating wall shear stress as for smooth annular duct, these data are presented in Figure 1. They are correlated by Eq. 4 with $\mathrm{m}=1$ and $\mathrm{B}^{\star}=1.45 \cdot 10^{-4} \mathrm{~K} \cdot \mathrm{s} / \mathrm{m}$.

All mentioned investigations were performed in laboratory conditions on small PHEs or experimental models of channel. The experimental study of precipitation fouling in industrial PHE for fresh water heating was reported by Chernyshov (2002). Alfa Laval M10B PHE of 78 plates was installed in District Heating (DH) system of city Tula in Russia. This DH system had obsolete nowadays "open circuit" of hot water supply, where hot water is just taken from radiator circuit. It required to heat fresh water to the temperatures of radiator circuit, much higher than in "closed radiator circuit" schemes. Because of high salts content in fresh water $(780 \mathrm{mg} / \mathrm{L})$ and necessity to heat it to temperatures $60-63{ }^{\circ} \mathrm{C}$ and more, heat exchanger experienced severe fouling. The fouling depends strongly from temperature of the heated fresh water and hence from the position along the plate length. The data on average asymptotic fouling thermal resistance, reported by Chernyshov (2002) at three different flow velocities (from $0.26 \mathrm{~m} / \mathrm{s}$ to $0.57 \mathrm{~m} / \mathrm{s}$ ), are presented on Figure 1 . The fouling thermal resistance calculated from data on fouling thickness and the value of fouling thermal conductivity $1.03 \mathrm{~m} \cdot \mathrm{K} / \mathrm{W}$. We have estimated wall shear stresses using Eq. 5 and Eq. 6, as described above. For water temperature $61{ }^{\circ} \mathrm{C}$, $\mathrm{De}=0.005 \mathrm{~mm}, \mathrm{y}=0.581$. Data correlated by Eq. 4 with $\mathrm{m}=1$ and $\mathrm{B}^{*}=115 \cdot 10^{-4} \mathrm{~K} \cdot \mathrm{s} / \mathrm{m}$. Slightly lower data for smallest velocity can be explained by relatively big fouling thickness (up to $0.8 \mathrm{~mm}$ ) compare to plate spacing $(2.5 \mathrm{~mm})$. It leads to decrease of real cross section area for water flow, higher velocity and higher shear stress, than calculated for clean channel cross section. 


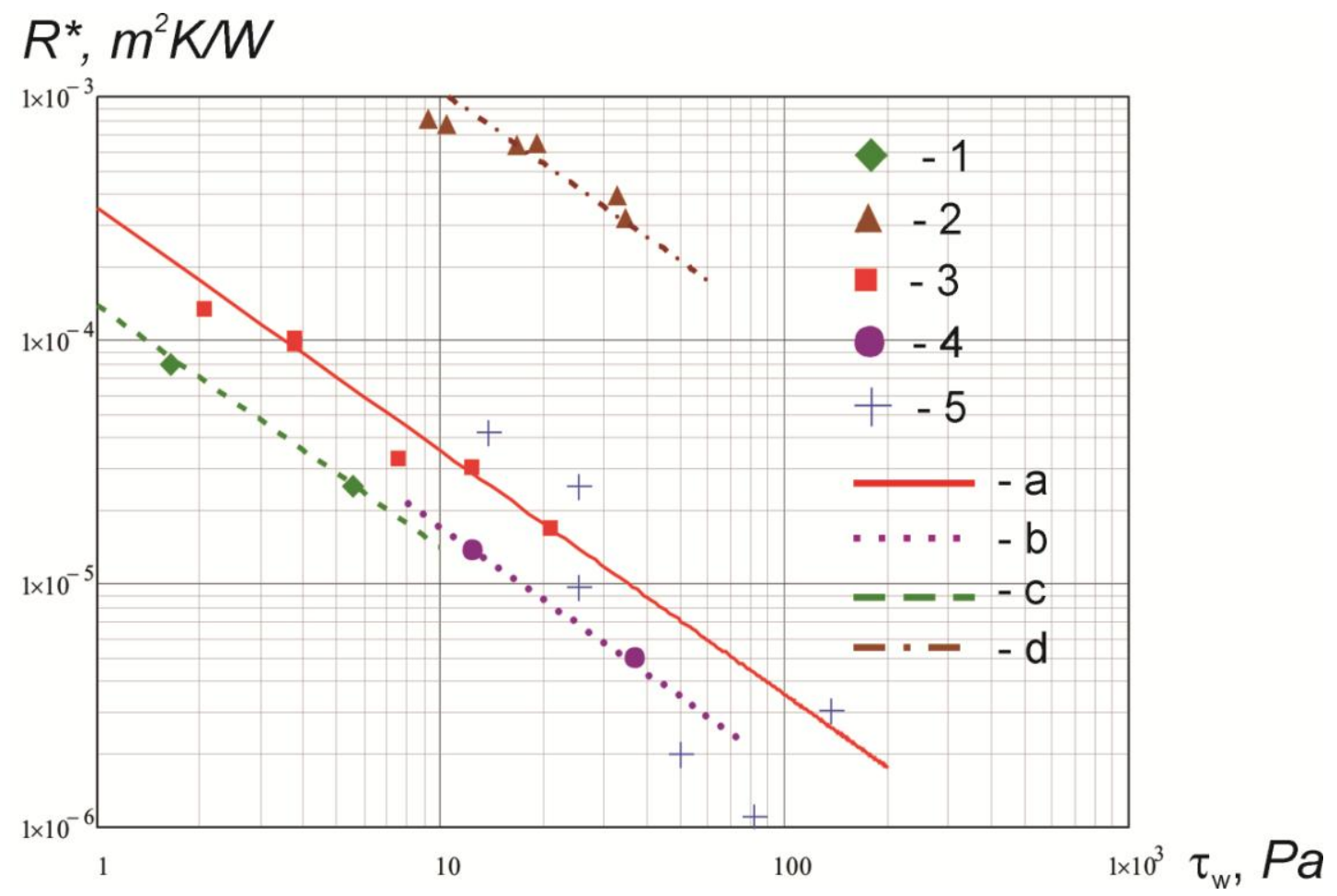

Figure 1: The influence of wall shear stress on asymptotic value of fouling thermal resistance: 1 and line $c$ - annular channel by Zhenhua et al. (2008); 2 and line $d-P H E$ channel $\beta=60^{\circ}$ by Chernyshov (2002); 3 and line a - PHE channel $\beta=30^{\circ} ; 5$ - PHE channel $\beta=60^{\circ}$ by Karabelas et al, (1997); 4 and line $b-P H E$ channel $\beta=60^{\circ}$ by Bansal et al. (2000);

The presented above data are obtained at four different conditions of water fouling. For the same level of wall shear stress the asymptotic values of fouling thermal resistance are much different. They depend on different factors: concentration, nature and size distribution of suspended particles; soluble salts concentration and different salts content; temperatures of water and the channel walls (see paper by Halalizadeh et al., 2000). But for the same water and temperature conditions the dependence of asymptotic fouling thermal resistance from wall shear stress is described by the same relation and is inversely proportional to wall shear stress. Counting on the assumptions made on deriving Eq. 4 we can conclude that the removal term $\varphi_{r}{ }^{*}$ in Equation 1 is proportional to wall shear stress in power $\mathrm{m}=1$. The determination of deposition term $\varphi_{d}{ }^{*}$, at the conditions when asymptotic fouling reached, is a very complicated task. A lot of parameters influence it. But for the big enterprise with certain water circuit the quality of the cooling water is the same for all coolers. In that case, when water asymptotic fouling in one heat exchanger can be determined, we can calculate the coefficient $B^{*}$ in Eq. 4 and use this value to determine cooling water fouling for PHEs calculated for this enterprise on all other cooling positions.

\section{Discussion of the results}

Analyzing the results we can conclude that presented mathematical model is capable to predict asymptotic values of fouling thermal resistance for precipitation and particulate fouling. The model can be used for PHEs with enhanced heat transfer and also for straight channels without heat transfer intensification. It predicts the effects of wall shear stress, but the influence of salts concentrations and solid particles content and sizes is not accounted.

The big industrial enterprises usually have quite a big numbers of heat exchangers, which are using water of the centralized cooling water circuit of the enterprise. The salts and solid particles contents in this water are the same for all heat exchangers. Therefore, by monitoring water side fouling 
development in one heat exchanger (in PHE or inside tubes of tubular heat exchanger) we can estimate parameters $B^{*}$. It will enable to account for cooling water fouling in all PHEs of this enterprise. For flows inside tubes and straight channels the calculation of wall shear stress is no problem, it can be made by formulas available in open literature. For PHEs the correlations for friction factor are usually proprietary by PHEs manufacturers. The important feature of the fouling prediction approach proposed here is that the wall shear stress is calculated based on Equations for friction factor on a main corrugated field of the PHE channel. To use this Equations engineer must know only the geometrical characteristics of the main corrugated field of the plates - the corrugation angle to longitudinal plate axis $\beta$ and corrugation aspect ratio $\gamma$, which can be measured on real plates.

\section{Conclusions}

The cooling water fouling in PHE channels have asymptotic character in time. When other fouling process conditions are equal, the asymptotic values of fouling thermal resistance are inversely proportional to wall shear stress. These phenomena for PHE channels, as also for straight channels and tubes, are similar in nature and can be described by the same empirical correlations.

For certain cooling water circuit of a big industrial enterprise this parameter can be determined by data about fouling in one heat exchanger. After that the model can be used for prediction of asymptotic thermal resistance of cooling water fouling in all heat exchangers for this circuit.

More experimental data are needed to estimate fouling thermal resistance just on a data of water purity and chemical content. By utilizing the proposed approach the data obtained for smooth channels can be used directly for PHEs and vice versa.

\section{Acknowledgement}

The support of EC Project INTHEAT (contract № FP7-SME-2010-1-262205) is sincerely acknowledged.

\section{References}

Arsenyeva O., Tovazhnyansky L., Kapustenko P., Khavin G., 2011, The generalized correlation for friction factor in crisscross flow channels of plate heat exchangers, Chemical Engineering Transactions, 25, 399-404.

Bansal B, Muller-Steinhagen H, Chen X.D, 2000, Performance of plate heat exchangers during calcium sulphate fouling - investigation with an in-line filter. Chemical Engineering and Processing, 39, 507-519.

Bansal B, Chena X.D, Muller-Steinhagen H., 2008, Analysis of 'classical' deposition rate law for crystallisation fouling. Chemical Engineering and Processing, 47, 1201-1210.

Chernyshov D.V., 2002, Prognosis of scaling in plate water heaters for increasing reliability of their operation., PhD Thesis, VAC RF 05.23.03, Tula, Russian Federation (in Russian). $<$ www.disserCat.com> (Ivisited 25.09.2011).

Halalizadeh A, Muller-Steinhagen H, Jamialahmadi M. 2000, Mixed salt crystallization fouling. Chemical Engineering and Processing, 39; 29-43.

Kapustenko P., Arsenyeva O., Dolgonosova O., 2011, The Heat and Momentum Transfers Relation in Channels of Plate Heat Exchangers, Chemical Engineering Transactions, 25, 357-362.

Karabelas A.J., Yiantsios S.G., Thonon B., Grillot J.M., 1997, Liquid side fouling of Heat Exchangers. An Integrated R\&D Approach for Conventional and Novel Designs. Applied Thermal Engineering, 7 (8-10), $727-737$.

Klemeš, J., Friedler, F., Bulatov, I., Varbanov, P., 2010, Sustainability in the Process Industry. Integration and Optimization, The McGraw-Hill Co-s. Inc., New York, USA.

Kukulka D.J., Czechowski H., Kukulka P.D.. 2010, Factors Associated With Fouling in the Process Industry. Heat Transfer Engineering, 31(9), 782-787.

Panchal C.B., Knudsen J.G., 1998, Mitigation of Water Fouling: Technology Status and Challenges. Advances in Heat Transfer, 31, 431 - 474. 
Shah, R.K., Sekulić, D.P., 2003, Fundamentals of Heat Exchanger Design, New York: Wiley and sons, USA.

Standards of the Tubular Exchanger Manufacturers Association, 2007, $9^{\text {th }}$ edn., TEMA Inc., New York, USA.

Quan Z, Chen Y, Ma Ch., 2008, Experimental Study of Fouling on Heat Transfer Surface During Forced Convective Heat Transfer. Chinese Journal of Chemical Engineering, 16(4), 535-540.

Tovazshnyansky, L.L., Kapustenko, P.O., Khavin, G.L., Arsenyeva, O.P., 2004, PHEs in Industry, Kharkiv: NTU KhPI, Ukraine (In Russian).

Wang, L., Sunden, B., Manglik, R.M., 2007, PHEs. Design, Applications and Performance, WIT Press, Southhampton, UK.

Wang Q.W., Lin, M., Zeng, M., 2009, Effect of lateral fin profiles on turbulent flow and heat transfer performance of internally finned tubes, Applied Thermal Engineering, 29, 3006-13

Yang M, Crittenden B., 2012, Fouling thresholds in bare tubes and tubes fitted with inserts. Applied Energy, 89, 67-73 